\title{
Augmented serum levels of the IGF-I/IGF-binding protein-3 ratio in pre-menopausal patients with type I breast cysts
}

\author{
Pablo J Enriori ${ }^{1}$, Carlos R Fischer ${ }^{2}$, Jorge R Gori ${ }^{2}$, Alberto E Etkin ${ }^{3}$, Ricardo S Calandra ${ }^{1,4}$ and Isabel A Lüthy ${ }^{1}$ \\ ${ }^{1}$ Instituto de Biología y Medicina Experimental, ${ }^{2}$ Hospital Alemán, ${ }^{3}$ Hospital Durand, Buenos Aires and ${ }^{4}$ Facultad de Ciencias Exactas, \\ Universidad Nacional de La Plata, Buenos Aires, Argentina
}

(Correspondence should be addressed to I A Lüthy, Obligado 2490, C1428ADN, Buenos Aires, Argentina; Email: iluthy@ibyme.dna.uba.ar)

\begin{abstract}
Objective: Gross cystic disease (GCD) is the most common benign breast pathology. Although breast cysts are not considered pre-malignant lesions, an increased risk of breast cancer has been reported for patients with type I cysts $\left(\mathrm{Na}^{+} / \mathrm{K}^{+}<3\right)$. Furthermore, an augmented IGF-I/IGF-binding protein-3 (IGFBP-3) ratio has been described in breast cancer patients. The objective was to evaluate serum IGF-I and binding protein concentrations of type I and type II cyst patients as compared with healthy women.

Methods: Twenty-four patients with type I cysts, 17 with type II cysts and 25 healthy women were evaluated. Serum IGF-I, IGFBP-3 and IGFBP-1 concentrations were measured by IRMA.

Results: IGF-I concentrations were significantly higher in sera from patients with type I cysts than in patients with type II cysts. A highly significant decrease of IGFBP-3, the major IGFBP, was found in patients with type I cysts with respect to healthy women, whereas no significant difference was evident between the different cyst types. The IGF-I/IGFBP-3 ratio, an estimate of biologically active IGF-I, was very significantly higher in patients with type I cysts than in both type II patients and healthy women. IGFBP-1 levels were significantly lower in patients with type I than in controls and type II cysts. The IGF-I/IGFBP-1 ratio was significantly higher in patients with type I cysts than in type II bearers and healthy women. Estrogen levels correlated with IGF-I in patients and controls.

Conclusions: The enhanced levels of IGF-I/IGFBP-3 found in patients with type I cysts could eventually be associated with the increased risk of breast cancer described for this group.
\end{abstract}

European Journal of Endocrinology 148 177-184

\section{Introduction}

Gross cystic disease (GCD) is the most common benign breast pathology. It has been reported that about $7 \%$ of women in Western countries develop a palpable cyst (1). The breast cysts originate from the terminal duct lobular units of the breast, which are also the site of origin of most proliferative breast lesions, including ductal and lobular in situ carcinoma (2). The composition of breast cyst fluid $(\mathrm{BCF})$ has been studied for the last 20 years $(3,4)$. A differential distribution of electrolytes, steroid and peptide hormones and growth factors has been found (5), suggesting that mammary cysts are complex endocrine entities capable of accumulating and probably synthesizing certain hormones (6). There are two clearly defined types of breast cysts. Type I cysts are lined by apocrine epithelium and contain fluid with an electrolyte composition similar to that of intracellular fluid (high concentrations of potassium $\left(\mathrm{K}^{+}\right)$, low concentrations of sodium $\left(\mathrm{Na}^{+}\right)$, a Na ${ }^{+} / \mathrm{K}^{+}$ratio $<3$, and high concentrations of conjugated steroid hormones and epidermal growth factor (EGF)) (7). Type II cysts have an electrolyte composition more similar to that found in plasma $\left(\mathrm{Na}^{+} / \mathrm{K}^{+}\right.$ratio $\left.>3\right)$ and lower concentrations of sex hormones and EGF (8).

Breast cysts are not considered pre-malignant lesions. Several reports, however, have indicated that bearers of cysts have a two- to fourfold higher risk of later developing cancer $(9,10)$. It has been described that the increased risk of breast cancer in women with breast cysts seems to be concentrated among women with type I breast cysts, with a relative risk of 4.2 (8). However, this last statement is still a matter of controversy (7).

Insulin-like growth factor-I and -II (IGF-I and IGF-II) are potent mitogens that play a pivotal role in regulating cell proliferation, differentiation and apoptosis. The effects of IGFs are mediated through the IGF-I receptor, which is also involved in cell transformation induced by 
tumor virus proteins and oncogene products (11). Six IGF-binding proteins (IGFBPs) can inhibit or enhance the actions of IGFs (12).

Epidemiological studies have found that high levels of circulating IGF-I and low levels of IGFBP-3 are associated with increased risk of breast cancer, suggesting a possible involvement of IGF-I and IGFBP3 in the development of the disease $(13,14)$. Other authors found this difference only in pre-menopausal women $(15,16)$. Nevertheless, two other reports showed no significant differences in either IGF-I or IGFBP-3, but these groups compared breast cancer patients with women with benign disease of the breast $(17,18)$. However, the possibility of altered values of IGF-I or IGFBP-3 in patients with benign disease cannot be discounted. Recently, two prospective epidemiological studies described an enhancement in circulating IGF-I, relating it to the risk of developing breast cancer in pre-menopausal women (19, 20). Very recently, another study described a similar association between free IGF-I levels and breast cancer (21).

The present data describe enhanced serum levels of bioavailable IGF-I, due to lower levels of IGFBP-1 and IGFBP-3 in patients with type I breast cysts. The levels found in these patients are similar to those described in the literature for women who develop breast cancer later in their lives.

\section{Subjects and methods}

\section{Subjects}

Seventy pre-menopausal women were studied. Forty-five of them were diagnosed as patients with GCD, classified according to Haagensen's criterion (cyst greater than $3 \mathrm{~mm}$ in diameter, as measured by ultrasound) (1). The other 25 women were healthy and fulfilled the necessary requirements to be controls: similar age range, $\mathrm{BMI}$ and menstrual cycle characteristics (Table 1).

Patients were analyzed because of a breast lump found by auto-examination, or clinical examination. All the patients were subjected to a physical examination, mammography, ultrasonic examination and fine-needle aspiration and cytology of the material aspirated. The cysts were aspirated only when the ultrasound diameter was greater than $3 \mathrm{~mm}$, either in the case of a single or multiple cysts. Cysts were aspirated

Table 1 Characteristics of controls and patients.

\begin{tabular}{lccc}
\hline & Controls & GCD & $\boldsymbol{P}$ value; significance \\
\hline$N$ & 25 & 45 & \\
Age (years) & $43.5 \pm 3.7$ & $44.6 \pm 4.8$ & $0.289 ; \mathrm{NS}$ \\
BMl (kg/m $\left.\mathrm{m}^{2}\right)$ & $22.8 \pm 2.6$ & $22.9 \pm 4.2$ & $0.918 ; \mathrm{NS}$ \\
Biphasic cycles & $72 \%$ & $69 \%$ & $0.785 ; \mathrm{NS}$ \\
Monophasic cycles & $28 \%$ & $31 \%$ & $0.785 ; \mathrm{NS}$ \\
\hline
\end{tabular}

for therapeutic reasons, as indicated by clinical consensus (22). The patients did not present a family history of breast cancer.

Control women did not present cysts, as ruled out by physical examination, mammography and ultrasound, and did not present any family history of breast cancer.

From the 45 patients with GCD, 31 presented a single cyst, four presented double cysts, and ten presented more than three cysts simultaneously. All the patients showed cysts greater than $3 \mathrm{~mm}$, and they were then all aspirated at least once. Only three patients recurred and none developed breast cancer during the study.

Patients were classified as possessing a type I cyst when the $\mathrm{Na}^{+} / \mathrm{K}^{+}$ratio in the $\mathrm{BCF}$ was $<3$, and type II in the opposite case. The majority of the patients with multiple cysts $(10 / 14)$ presented the same kind of cyst, and the four patients that presented mixed cysts were excluded. Post-menopausal women, patients with either endocrine pathologies or breast cancer and pregnant women were also excluded from the study. Therefore all patients and controls were menstruating regularly, and none of them had used oral contraceptives in the 6 months prior to the study. A pre-menopausal woman was defined as a female who had regular menstrual periods 3 months before entering the study and had adequate levels of estradiol and gonadotropins. Women with ovulatory biphasic cycles were defined by serum progesterone concentrations $>2.5 \mathrm{ng} / \mathrm{ml}$ during the luteal phase (LPh, between days 20 and 23). When serum progesterone concentrations were $<2.5 \mathrm{ng} / \mathrm{ml}$ during days 20-23, the cycle was considered monophasic. The percentage of women with undetermined monophasic cycles was around $25 \%$ in both healthy women and patients. This percentage is adequate for peri-menopausal women who have a higher frequency of anovulation compared with younger women with a normal menstrual cycle (23).

Both patients and controls were examined in two medical centers by two different well trained ultrasound observers.

BCF aspiration was performed during the early follicular phase of the menstrual cycle (FPh, between days 3 and 7) with blood extraction at early $\mathrm{FPh}$ and $\mathrm{LPh}$.

The protocol was approved by two local Ethics Committees (Hospital Alemán and Instituto de Biología y Medicina Experimental) according to the Helsinki II Declaration.

\section{Methods}

Assays A fasting blood sample was obtained from each subject between 0830 and $1100 \mathrm{~h}$, serum collected and stored at $-20{ }^{\circ} \mathrm{C}$ until assayed. All samples from an individual woman were analyzed in duplicate in the same assay for each hormone. 
Sex steroids and gonadotropins were studied in order to establish menstrual characteristics. Estradiol and progesterone were measured by RIA (Diagnostic System Laboratories, Inc., Webster, TX, USA). The assay sensitivities were $4.7 \mathrm{pg} / \mathrm{ml}$ and $0.1 \mathrm{ng} / \mathrm{ml}$ respectively, intra-assay coefficients of variation (CVs) were $5.3 \%$ and $5.6 \%$, and interassay CVs were $9.3 \%$ and $10.2 \%$.

Serum luteinizing hormone (LH) and follicle-stimulating hormone (FSH) measurements were done by chemiluminescence (IMMULITE, Diagnostic Products Corporation, LA, USA). The assay sensitivities were $0.7 \mathrm{mUI} / \mathrm{ml}$ and $0.1 \mathrm{mUI} / \mathrm{ml}$ respectively, intra-assay CVs were $4.8 \%$ and $6.1 \%$ respectively, and interassay CVs were $10.6 \%$ and $6.5 \%$ respectively for the range of values measured.

IGF-I was determined in serum by IRMA after separation of IGFs from IGFBPs by acid-ethanol extraction (Diagnostic System Laboratories, Inc.). The detection limit was $0.80 \mathrm{ng} / \mathrm{ml}$, intra-assay CV (measured in our own hands) was $4.4 \%$ and interassay $\mathrm{CV}$ was $6.5 \%$.

Total IGFBP-3 and IGFBP-1 levels were assayed using IRMA assay kits supplied by Diagnostic System Laboratories, Inc. Reported intra-assay CVs were $2.7-5.2 \%$ for IGFBP- 1 and $1.8-3.9 \%$ for IGFBP-3; interassay CVs were $3.5-6.0 \%$ and $0.5-1.9 \%$ respectively.

$\mathrm{Na}^{+}$and $\mathrm{K}^{+}$concentrations in BCF were measured by flame spectrophotometry (EEL Flame Photometer) at dilutions $1: 100$ and 1:500 respectively.

\section{Statistical analysis}

Since IGF-I, IGFBP-1 and IGFBP-3 concentrations are widely dispersed, non-parametric statistical methods were used. Kruskal-Wallis test, followed by Dunn's test (24), was used to compare levels of these proteins between groups. A Chi square test was performed in order to evaluate the proportion of cases and controls with IGF $<207 \mathrm{ng} / \mathrm{ml}$ (19). Fisher's Exact test was used to evaluate the monophasic/biphasic menstrual cycle, an unpaired $t$-test was used for comparing age and BMI between controls and patients, and Spearman's rank correlation was used to correlate IGF-I concentrations with both binding proteins and with estradiol concentration in the FPh (24). A difference was considered significant when $P<0.05$.

\section{Results}

Serum IGF-I concentrations for 25 healthy women and 41 patients bearing a single type of breast cyst were measured. As summarized in Fig. 1, these results were significantly different when patients with type I cysts were compared with type II cyst. The percentage of patients with serum IGF-I levels higher than $207 \mathrm{ng} / \mathrm{ml}$, the cut-off value described by Hankinson et al. (19) as the predictive concentration for increased risk of breast cancer, was also significantly higher in patients with type I cysts when compared with type II using the Chi square test.

As the major IGF-binding protein is type 3, its concentration was measured in these serum samples. Fig. 2 (top panel) depicts this concentration, showing a highly significant decrease in patients with type I cysts with respect to controls. In this case, no significant difference was found between the different cyst

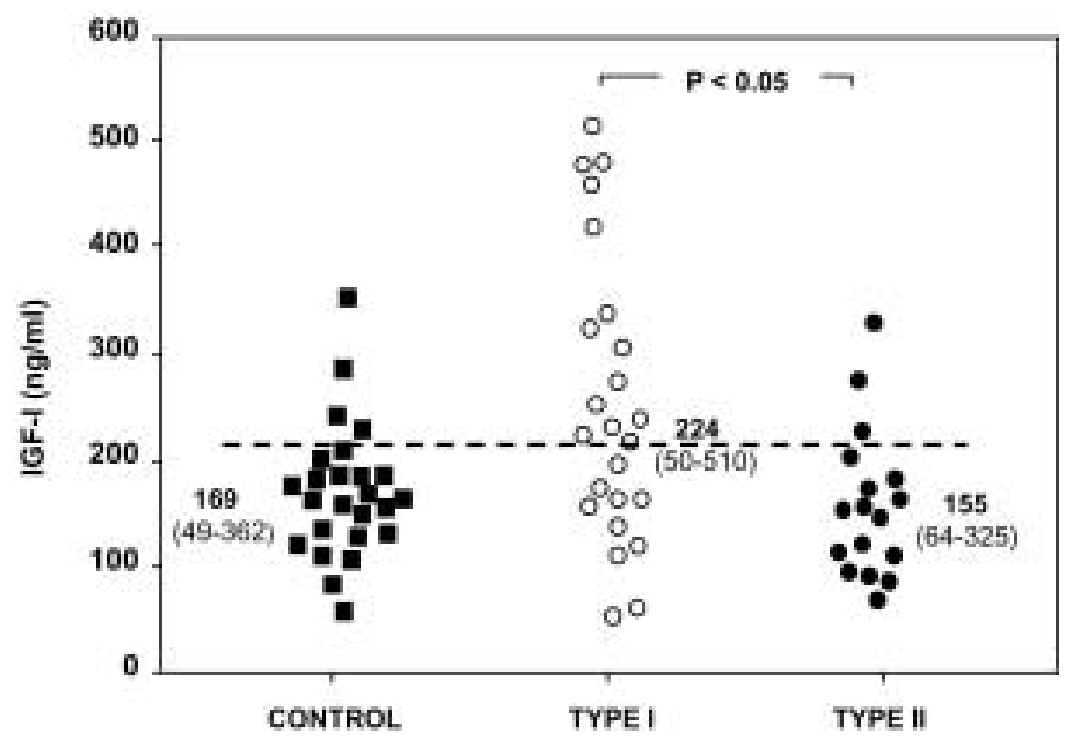

Figure 1 Serum IGF-I concentrations in controls $(\boldsymbol{\square} ; n=25)$ and patients with type I $(0 ; n=24)$ and type II $(\bullet ; n=17)$ cysts. The numerical values are the median and range of each group. Statistical analysis was performed using the Kruskal-Wallis test, followed by Dunn's test. The dotted line indicates the cut-off value described by Hankinson et al. (19). 

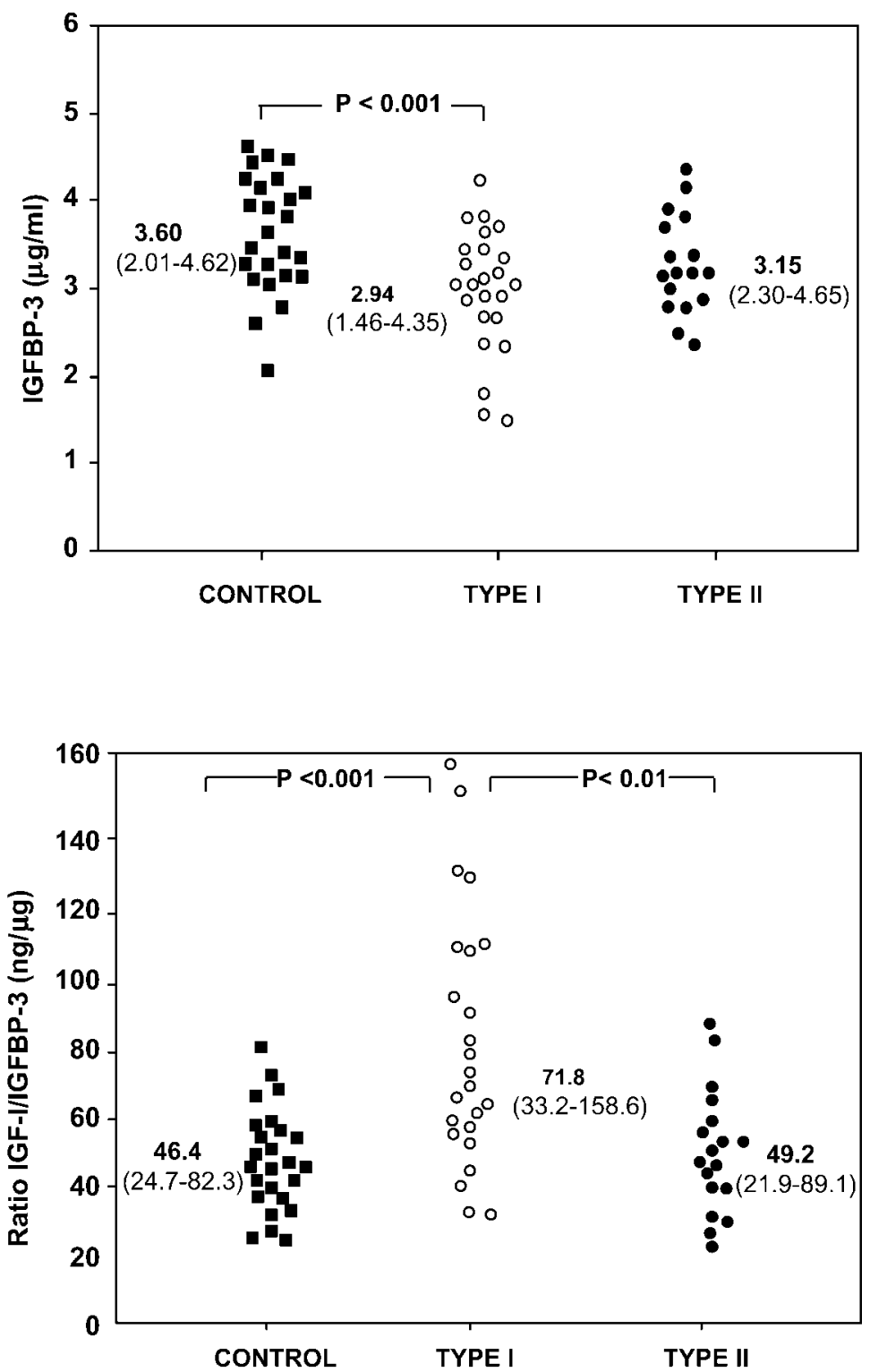

Figure 2 Serum IGFBP-3 concentrations (top panel) and IGF-I/IGFBP-3 ratio (bottom panel) in controls ( $\mathbf{\square})$ and patients with type I (O) and type II (๑) cysts. The numerical values are the median and range for each group. Statistical analysis was performed using the Kruskal-Wallis test, followed by Dunn's test.

types. As the IGF-I/IGFBP-3 ratio is an estimate of free and biologically active IGF-I, we expressed the results previously shown as this ratio (Fig. 2, bottom panel). As can be seen in this figure, this ratio was very significantly higher in patients with type I cysts than both type II and healthy control patients. As has already been described by several groups, the IGFBP-3 concentration correlated significantly with IGF-I levels in controls $(r=0.562, P<0.003)$. This correlation was also found in patients with GCD $(r=0.533$, $P<0.001)$. We were also interested in determining the IGFBP-1 concentration and its calculated ratio to IGF-I due to the fact that this binding protein is not directly regulated by the same hormone that regulates the growth factor. IGFBP-1 levels (Fig. 3, top panel) were significantly lower in patients with type I cysts than with type II cysts. In addition, IGFBP-1 levels do not correlate with IGF-I concentrations in controls $(r=-0.027$, NS) or in patients with GCD $(r=-0.088$, NS) (data not shown). The IGF-I/ IGFBP-1 ratio, depicted in Fig. 3, bottom panel, was significantly higher in patients with type I cysts than in type II bearers.

Serum levels of estradiol during the FPh were analyzed in serum from the healthy women and cyst patients. Healthy women showed $39.2 \pm 5.1 \mathrm{pg} / \mathrm{ml}$, the whole 

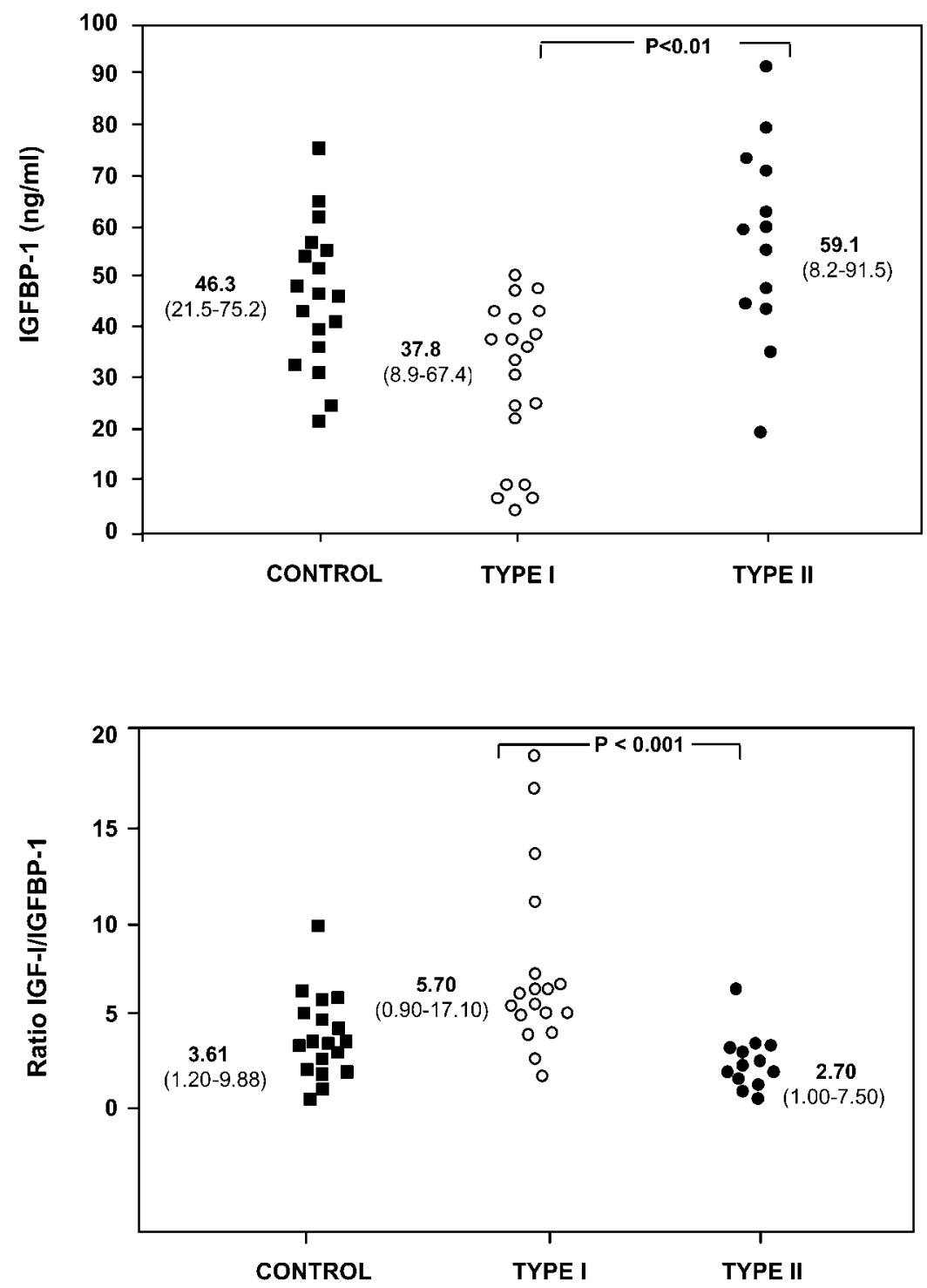

Figure 3 Serum IGFBP-1 concentrations (top panel) and IGF-I/IGFBP-1 ratio (bottom panel) in controls ( $\square$ ) and patients with type I (O) and type II (๑) cysts. The numerical values are the median and range for each group. Statistical analysis was performed using the Kruskal-Wallis test, followed by Dunn's test.

group of patients $42.2 \pm 3.8 \mathrm{pg} / \mathrm{ml}$, type I bearers alone $46.6 \pm 5.6 \mathrm{pg} / \mathrm{ml}$, and patients with type II cysts $35.6 \pm$ $5.7 \mathrm{pg} / \mathrm{ml}$. These values were not significantly different in any case as analyzed using the Kruskal-Wallis nonparametric test. As shown in Fig. 4, serum IGF-I levels correlate with estradiol concentrations in both healthy women (top panel) and patients (bottom panel).

\section{Discussion}

IGF-I is a systemic growth factor with potent mitogenic and anti-apoptotic properties, which could influence the proliferative behavior of normal breast cells. As has already been stated, prospective epidemiological studies have offered growing evidence that increased concentrations of IGF-I in the circulation of pre-menopausal women may be related to breast cancer risk. Such an association may be even stronger when the IGF-I/IGFBP-3 ratio is utilized as a measure of IGF-I available for biological activity $(19,20)$. On the other hand, some studies have found an association between type I breast cysts and risk of breast cancer $(8,25)$. It should be noted that breast cysts are not considered to be pre-malignant lesions but simple markers of an increased risk affecting the whole organ (8). Even if the difference in cancer risk between cysts types is not accepted by the whole scientific community (7), we found it worth exploring the possibility that IGF-I 

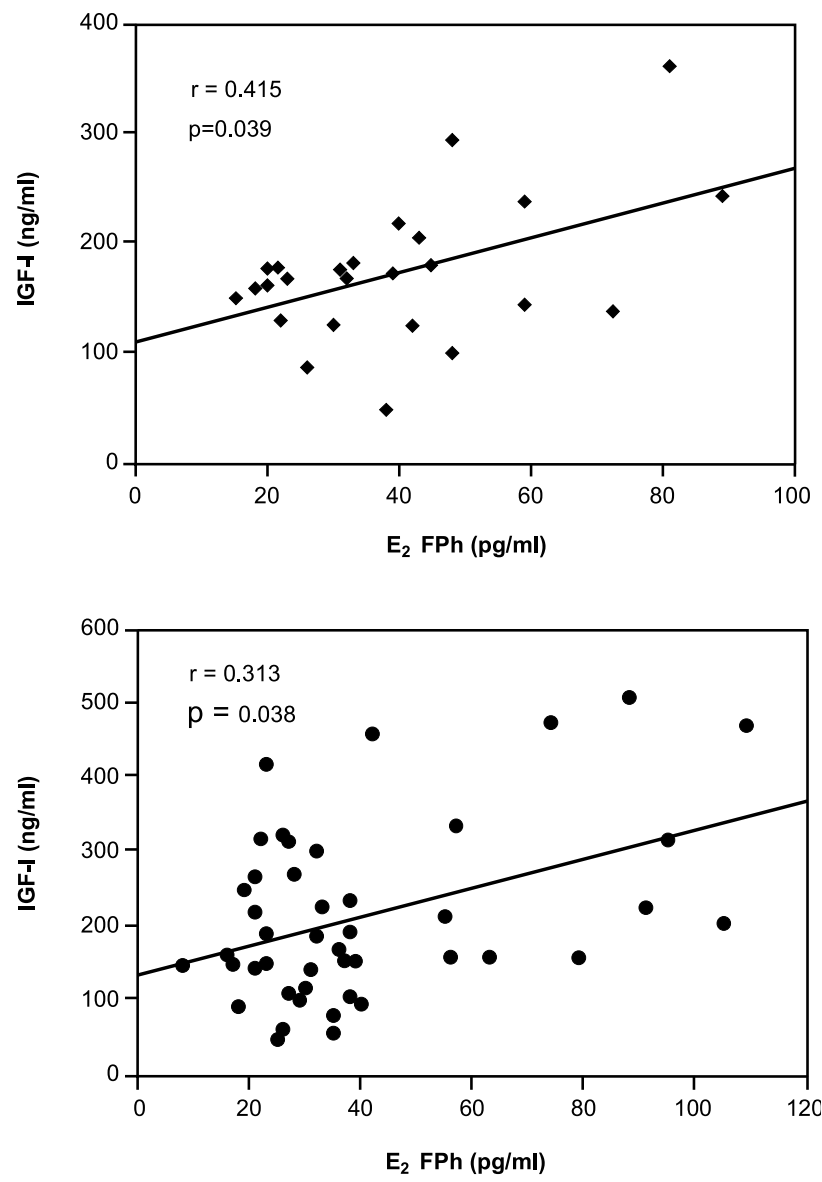

Figure 4 Correlation between serum IGF-I and estradiol $\left(E_{2}\right)$ concentrations during the FPh in healthy women (top panel) and patients (bottom panel). The data were analyzed using Spearman's rank correlation.

and, especially, the IGF-I/IGFBP-3 ratio (which can be interpreted as a measure of IGF-I bioavailability) could be, at least in part, one of the causes of the increased risk in breast cancer. We have consequently analyzed serum levels of IGF-I and two of its binding proteins in healthy women and patients with breast cysts, a common benign disease in pre-menopausal women.

Serum levels of IGF-I were measured in 41 patients and 25 healthy women. Patients bearing type I cysts showed higher levels of serum IGF-I than those with type II cysts. To our knowledge, no data are available in the literature related to serum IGF-I levels and the $\mathrm{Na}^{+} / \mathrm{K}^{+}$ratio in cysts. Bearing in mind the possibility of an association of cyst patients in general with an increased risk of breast cancer, and the increase in serum IGF-I levels several years before the appearance of cancer, these results failed to show an association between these two observations. However, a non-significant increase was found in these levels when the whole group of patients and controls were compared, or when type I bearers were compared with controls. Yet, the significant difference in serum IGF-I levels between the different cyst types was an interesting finding. In the Nurses Health Study, Hankinson et al. (19) established a cut-off value of $207 \mathrm{ng} / \mathrm{ml}$ to discriminate relative risk of breast cancer. These authors have established tertiles instead of quintiles for IGF-I serum values in their pre-menopausal controls because of the smaller numbers. The cut-off value chosen discriminates between the top vs medium and bottom tertiles in pre-menopausal controls. In the present analysis, we used the same kit as Hankinson's group for measuring IGF-I and IGFBP-3. Our cohort of controls was not large enough to establish our own cut-off value. Nevertheless, the median value for the determinations of controls by Hankinson's group (19) was similar to ours (169.0 vs 175 for controls). Choosing this cut-off value, we calculated the proportion of controls and patients of each group above and below it. A significant difference was found by the Chi square test in the proportion of controls and patients with type I with values above and below the cut-off.

IGFBP-3 is the most abundant IGFBP in postnatal serum, existing at levels an order of magnitude higher than other IGFBPs. IGFBP-3 does not change acutely (26). Type I patients showed lower IGFBP-3 levels than controls. Type II patients exhibited intermediate levels not significantly different from either controls or type I cysts. The IGF-I/IGFBP-3 ratio was markedly discriminatory between the study groups, showing significant differences between type I vs control group and type I vs type II patients. This result is the most relevant finding in this study, since it can be interpreted as a measurement of IGF-I bioavailability. The lower levels of IGFBP-3 found in type I cyst patients should not be interpreted as an alteration of the regulation by $\mathrm{GH}$, since IGF-I concentration correlated with IGFBP-3 in a similar manner to controls. This correlation in healthy women confirms previous results $(27,28)$.

IGFBP-1 was chosen as another IGFBP due to its different regulation with respect to IGFBP-3. Although some cytokines can stimulate IGFBP-1 in vitro and in vivo, serum IGFBP-1 levels are predominantly regulated by insulin and cortisol levels through transcriptional control of hepatic IGFBP-1 synthesis (26). IGFBP-1 showed diminished levels in type I patients with respect to type II bearers. An analysis of the IGF-I/IGFBP-1 ratio showed a similar pattern to that of the IGFI/IGFBP-3 ratio, although the amount of IGF-I bound to IGFBP-1 is considerably lower. In adults, it has been reported that there is a substantial genetic contribution responsible for inter-individual variation of the circulating levels of IGF-I and IGFBP-3, whereas no significant heritability was found for IGFBP-1 concentrations $(29,30)$.

Some interactions between IGF-I and estrogen have been described by other groups. In breast cancer cells, estrogens enhance the mitogenic effect of IGF-I, 
induce expression of IGF-I, and stimulate production of IGF-I receptors (11). Tamoxifen, which is anti-estrogenic in breast tissue, abolishes the effects of estrogens on IGF-I, inhibits transcription of IGF-I, and attenuates the response of the IGF-I receptor (11). In contrast to other reports, recent analysis using longitudinal (within-subject) comparisons in the same menstrual cycle, further disclosed that plasma IGF-I concentrations rise concomitantly in the pre-ovulatory phase with the serum estradiol zenith (31). Serum estrogen levels were then measured for controls and patients. No significant differences were observed when controls were compared with both the whole group of patients or either cyst type bearers. On the other hand, IGF-I concentrations were correlated significantly with estradiol during the $\mathrm{FPh}$ in both controls and patients. As estrogen levels were similar in each group, the differences found in the IGF-I/IGFBP-3 system could not be ascribed to estrogen action.

Women with biphasic cycles showed a higher frequency of type I cysts (73\%) whereas women with monophasic cycles had a higher frequency of type II cysts $(60 \%)$, as analyzed by Fisher's exact test. This fact could suggest that serum progesterone levels could be related to cyst type.

Only three patients recurred during the study. This fact precludes correlations between outcome and IGF-I or IGF-I/IGFBP-3 values. No case of breast cancer was found in the patients after the cysts were aspired. However, in the future, these patients will be followed in order to analyze these possibilities.

The present results show a clear and very significant enhancement of serum IGF-I/IGFBP-3 ratio in patients with type I cysts as compared with both controls and type II cyst-bearers. It might be considered that the up to sevenfold increase in breast cancer risk among pre-menopausal women $-\leq 50$ years old - suggests that the relation between IGF-I and risk of breast cancer may be greater than that of other established breast cancer risk factors, with the exception of a strong family history of breast cancer or a high density mammographic profile (19). As breast cysts are not pre-neoplasic lesions, certain factors - such as hormones and growth factors, most probably - could be related to the described enhanced risk of breast cancer in breast cyst patients, especially those with type I cysts. Therefore, it could be speculated that the elevation of IGF-I bioavailability in type I cyst bearers could eventually enhance breast cancer risk, probably stimulating proliferation of the terminal duct lobular units of the breast, the site of origin of both breast cysts and breast cancer.

\section{Acknowledgements}

This work was supported by the Fundación Alberto J Roemmers, the Consejo Nacional de
Investigaciones Científicas y Técnicas (CONICET), and Agencia Nacional de Promoción Científica y Tecnológica (FONCYT), Argentina. RSC and IAL are members of the Research Career, CONICET, Argentina.

\section{References}

1 Haagensen CD, Bodian C \& Haagensen DE Jr (Eds). Gross cystic disease of the breast. In Breast Carcinoma: Risk and Detection, pp 55-75. Philadelphia: W B Saunders, 1981.

2 Zanardi S, Pensa F, Torrisi R, De Franchis V, Barreca A, Minuto F et al. Presence and distribution of growth factors in breast cyst fluid. Annals of the New York Academy of Sciences $1996 \mathbf{7 8 4}$ 542-549.

3 Bradlow HL, Rosenfeld RS, Kream J, Fleisher M, O'Connor J \& Schwartz MK. Steroid hormone accumulation in human breast cyst fluid. Cancer Research 1981 41 105-107.

4 Bélanger A, Caron S, Labrie F, Naldoni C, Dogliotti L \& Angeli A. Levels of eighteen non conjugated and conjugated steroids in human breast cyst fluid: relationships with cyst type. European Journal of Cancer 199016 277-281.

5 Enriori CL, Novelli JE, Cremona MC, Hirsig RJP \& Enriori PJ. Biochemical study of cyst fluid in human breast cystic disease: a review. Breast Cancer Research and Treatment 199224 1-9.

6 Dogliotti L, Orlandi F, Caraci P, Puligheddu B, Torta M \& Angeli A. Biochemistry of breast cyst fluid: an approach to understanding intercellular communication in the terminal duct lobular units. Annals of the New York Academy of Sciences $1990 \mathbf{5 8 6} 17-28$.

7 Dixon JM, McDonald C, Elton RA \& Miller WR. Risk of breast cancer in women with palpable breast cysts: a prospective study. Lancet $19993531742-1745$.

8 Bruzzi P, Dogliotti L, Naldoni C, Bucchi L, Constantini M, Cicognani A et al. Cohort study of association of risk of breast cancer with cyst type in women with gross cystic disease of the breast. British Medical Journal $1997314925-928$.

9 Bodian CA. Benign breast diseases, carcinoma in situ, and breast cancer risk. Epidemiological Reviews 199315 177-187.

10 Angeli A, Dogliotti L, Naldoni L, Puligheddu B, Caraci P, Bucchi L et al. Steroid biochemistry and categorization of breast cyst fluid: relation to breast cancer risk. Journal of Steroid Biochemistry and Molecular Biology 199449 333-339.

$11 \mathrm{Yu} \mathrm{H} \&$ Rohan T. Role of the insulin-like growth factor family in cancer development and progression. Journal of the National Cancer Institute $2000921472-1489$.

12 Dubaquié Y, Mortensen DL, Intintoli A, Hogue DA, Nakamura G, Rancatore $\mathrm{P}$ et al. Binding protein-3-selective insulin-like growth factor I variants: engineering, biodistributions, and clearance. Endocrinology $2001 \mathbf{1 4 2} 165-173$.

13 Peyrat JP, Bonneterre J, Hecquet B, Vennin P, Louchez MM, Fournier C et al. Plasma insulin-like growth factor-1 (IGF-1) concentrations in human breast cancer. European Journal of Cancer $199329492-497$.

14 Kaulsay KK, Ng EH, Ji CY, Ho GH, Aw TC \& Lee K-O. Serum IGF-I binding protein- 6 and prostate specific antigen in breast cancer. European Journal of Endocrinology 1999140 164-168.

15 Bruning PF, Van Doorn J, Bonfrer JM, Van Noord PA, Korse CM, Linders TC et al. Insulin-like growth factor-binding protein-3 is decreased in early-stage operable pre-menopausal breast cancer. International Journal of Cancer 199562 266-270.

16 Bohlke K, Cramer DW, Trichopoulos D \& Mantzoros CS. Insulinlike growth factor-I in relation to pre-menopausal ductal carcinoma in situ of the breast. Epidemiology $19989570-573$.

17 Ng EH, Ji CY, Tan PH, Lin V, Soo KC \& Lee OK. Altered serum levels of insulin-like growth factor-binding proteins in breast cancer patients. Annals of Surgical Oncology $19985194-201$.

18 Del Giudice ME, Fantus IG, Ezzat S, McKeownn-Eyssen G, Page D \& Goodwin PJ. Insulin and related factors in pre-menopausal 
breast cancer risk. Breast Cancer Research and Treatment 199847 $111-120$.

19 Hankinson SE, Willett WC, Colditz GA, Hunter DJ, Michaud DS, Deroo B et al. Circulating concentrations of insulin-like growth factor-I and risk of breast cancer. Lancet 1998351 1393-1396.

20 Toniolo P, Bruning PF, Akhmedkhanov A, Bonfrer JMG, Koening KL, Lukanova A et al. Serum insulin-like growth factor-I and breast cancer. International Journal of Cancer 2000 88 828-832.

21 Li BDL, Khosravi MJ, Berkel HJ, Diamandi A, Dayton MA, Smith M et al. Free insulin-like growth factor-I and breast cancer risk. International Journal of Cancer 200191 736-739.

22 Leiss PH Jr. Gross breast cyst: significance of apocrine type, identification by cyst fluid analysis and management. Breast Disease 19936 185-194.

23 Metcalf MG, Donald RA \& Livesey JH. Pituitary-ovarian function in normal women during the menopausal transition. Clinical Endocrinology $1981 \mathbf{1 4} 245-255$.

24 Dowdy S \& Wearden S. Statistics for Research, pp 243-286. New York: John Wiley \& Sons, 1983.

25 Boccardo F, Marenghi C, Ghione G, Pepe A, Parodi S \& Rubagotti A. Intracystic epidermal growth factor level is predictive of breast-cancer risk in women with gross cystic disease of the breast. International Journal of Cancer (Predictive Oncology) $200195260-265$.

26 Ferry RJ, Bingrong L \& Cohen P. New roles for IGF binding proteins. Endocrinologist $19999438-450$.

27 Blum W, Albertsson-Wikland K, Rosberg S \& Ranke MB. Serum levels of insulin-like growth factor I (IGF-I) and IGF binding protein 3 reflect spontaneous growth hormone secretion. Journal of Clinical Endocrinology and Metabolism 1993 76 1610-1616.

28 Juul A, Main K, Blum W, Lindhom J, Ranke MB \& Skakkebaek NE The ratio between levels of insulin-like growth factor (IGF-I) and the IGF binding proteins (IGFBP-1, 2, and 3) decreases with age in healthy adults and is increased in acromegalic patients. Clinical Endocrinology 199441 85-93.

29 Harrela M, Koistinen H, Kaprio J, Lehtovirta M, Tuomilehto J, Eriksson J et al. Genetic and environmental components of interindividual variation in circulating levels of IGF-I, IGF-II, IGFBP-1 and IGFBP-3. Journal of Clinical Investigation $1996 \mathbf{9 8}$ $2612-2615$.

30 Jernstrom H, Deal C, Wilkin F, Chu W, Tao Y, Majeed N et al. Genetic and nongenetic factors associated with variation of plasma levels of Insulin-like Growth Factor-I and Insulin-like Growth Factor-Binding Protein-3 in healthy premenopausal women. Cancer Epidemiology, Biomarkers and Prevention 200110 $377-384$.

31 Ovesen P, Vahl N, Fisker S, Veldhuis JD, Sandahl J, Christiansen JS et al. Increased pulsatile, but not basal, growth hormone secretion rates and plasma insulin-like growth factor I levels during the periovulatory interval in normal women. Journal of Clinical Endocrinology and Metabolism 199883 1662-1667.

Received 5 June 2002

Accepted 4 November 2002 